\title{
Online Retail Store Community Engagement and Its Impact on Purchase Intentions in the Context of Online Reviews
}

\author{
Cara Peters, Winthrop University, USA \\ (iD) https://orcid.org/0000-0002-1091-5621 \\ Charles D. Bodkin, The University of North Carolina at Charlotte, USA
}

\begin{abstract}
Consumers want to engage with the retail store community in the shopping context. This study examines how consumers' perceptions of source credibility and perceived usefulness of online reviews impact an intention to engage with the online retail store community and purchase intentions. The study also identifies differences when reviews are posted by customers versus store employees. Results show that the proposed relationships within the structural model are significant, and reviews posted by store employees are seen as more credible, whereas reviews posted by other customers are perceived to be more useful. Theoretical and managerial implications are discussed.
\end{abstract}

\section{KEYWORDS}

Online Reviews, Perceived Usefulness, Purchase Intentions, Retail Store Community Engagement, Source Credibility

\section{INTRODUCTION}

Shopping is an inherently social experience (Carter, 2020). Whether it be shopping with friends and family, interacting with other shoppers or salespeople, or chatting with store employees at checkout, customers have reported that shopping in the retail store is communal in nature (Borghini et al., 2009; Jones \& Kim, 2011; Peters \& Bodkin, 2018). However, as shopping has increasingly moved online, due to convenience factors and the more recent pandemic stay-at-home orders, one may question whether the communal nature of shopping that exists in retail stores applies when customers are shopping online.

Practitioners are advocating that the social nature of shopping still exists when customers move online but in a way that differs from shopping in traditional retail stores (Beaulac, 2019; McIntyre, 2020). "Social shopping" is defined as customers going online to find reviews and recommendations about products and then using those reviews to guide purchase decisions (Widmer, 2020). The concept of "social shopping" is significant, as $93 \%$ of consumers have anecdotally reported that online reviews have impacted their purchase decisions (Widmer, 2020).

The purpose of this study is to examine the communal nature of utilizing online reviews for online shopping. There is a growing literature on community in physical stores, but marketers need greater understanding of community within online retailing. In addition, there are few papers that examine source credibility and perceived usefulness as they relate to community engagement in the context of 
online reviews, factors which may be important to social shopping. And while the literature suggests that shoppers view both customers and store employees as members of the retail store community, few studies to date have unpacked differences that may exist when online reviews are provided by these disparate sources. Thus, this study examines the following research questions to address the gaps in the literature: How do consumers' perceptions of source credibility and usefulness of online reviews, impact feelings of community and purchase intentions when posted by customers and store employees? Furthermore, do these relationships differ when the post is provided by other customers versus store employees?

\section{LITERATURE REVIEW AND HYPOTHESES}

While there is plethora of studies on community in marketing, the literature on retail store community is just beginning and has been mostly focused on physical stores, as opposed to online shopping (Borghini et al., 2009; Jones \& Kim, 2011; Peters \& Bodkin, 2018). And while there are numerous papers on online reviews, there are virtually no studies to date examining the impact of reviews on community engagement in the context of online shopping. Although this study is primarily grounded in theory on community, theories related to online reviews were also incorporated into the development of the hypotheses.

\section{Source Credibility}

Source credibility's impact on the believability of online reviews (Tahir \& Khan, 2020), as well as its impact on purchase intentions in the context of online reviews (Assaker, 2020; Kiran \& Srivastava, 2020; Xu et al., 2020), has been well established in the literature. There are no studies to date, however, that have examined the relationship between the source credibility of online reviews and consumers' intention to engage in an online retail community. The literature on virtual community shows that the credibility of information posted within these types of communities is of utmost importance to consumers. For example, Hajli et al. (2015) studied an online health community and found that consumers often questioned whether the other peoples' posts were credible and accurate. Chou et al. (2015) examined a virtual community and found that source credibility predicted the adoption of knowledge from the group. Nair and Harshavardhini (2002) also found that source credibility impacted eWOM adoption through perceived usefulness. Chih et al. (2013) surveyed a fashion community and found that website reputation, source credibility, obtaining buying information, and social orientation influenced perceived review credibility, and in turn attitudes and purchase intentions. Thus, based on the role of source credibility theory in the context of online reviews, as well as studies examining the impact of source credibility within virtual communities, the following hypotheses are posited:

Hypothesis One: In the context of online reviews, source credibility has a positive effect on online retail store community engagement intention.

Hypothesis Two: In the context of online reviews, source credibility has a positive effect on purchase intention.

\section{Perceived Usefulness}

Davis (1989) introduced the technology acceptance model (TAM), which identifies ease of use and perceived usefulness as determinants of the use of technology, to the field of information systems. The TAM model was introduced in a work context but has been applied in other consumer contexts, including e-commerce and online reviews (Bernardino et al., 2020; Kiran \& Srivastava, 2020; Ventre $\&$ Kolbe, 2020). The model has also been utilized in the literature on social commerce and virtual community. Zhang et al. (2016) examined social commerce among Chinese consumers and found that website quality, trust, and eWOM influenced online purchase intentions with perceived ease 
of use and perceived usefulness moderating the relationship between website quality and purchase intentions. More recent studies have also confirmed a direct relationship between perceived usefulness and purchase intentions (Kiran \& Srivastava, 2020; Xh et al., 2020; Ventre \& Kolbe, 2020; Zhang et al., 2021).

Xie et al. (2020) found that, within social commerce, user satisfaction, IT self-efficacy, user relationship network structure, platform quality, perceived usefulness, and emotional attachment significantly impact users' intentions to adopt information. Similarly, Assaker (2020) found that perceived usefulness, trustworthiness, expertise, and ease of use were significantly related to usage intention of online reviews, with these relationships differing by age and gender. The impact of perceived usefulness on the adoption of information provided in reviews has been reinforced in more recent studies as well (Nair \& Harshavardhini, 2020).

The virtual community literature has also identified perceived usefulness as a significant predictor of consumers' intention to engage with the community and adopt information from the group. Corkindale et al. (2018) identified trust and interface design as factors that drove consumers' intention to engage with a firm-hosted online community, with perceived usefulness mediating these relationships. Gadgil et al. (2018) conducted a study of an HIV virtual community and found that perceived usefulness and information quality were the two primary factors that influenced the quality of support and continued user engagement among group members. Other studies in the literature on virtual community have also reinforced perceived usefulness, among other variables, as significantly impacting consumers' intentions to engage with an online community (Chen \& Qi, 2015; Wang et al., 2012). Tsai et al. (2011) examined online group buying, and found that perceived usefulness, a sense of virtual community, and trust in the community were determinants of purchase intentions. Thus, based on studies utilizing TAM variables in the context of online reviews, as well as papers identifying the impact of perceived usefulness on intentions to engage and purchase in the contexts of social commerce and virtual communities, the following hypotheses are posited:

Hypothesis Three: In the context of online reviews, perceived usefulness has a positive effect on online retail store community engagement intention.

Hypothesis Four: In the context of online reviews, perceived usefulness has a positive effect on purchase intention.

\section{Online Retail Store Community Engagement Intention}

Early on, the literature on brand community found that an intention to engage with the group impacted brand loyalty, which encompasses both attitudinal and behavioral components (McAlexander et al. 2002). As the community literature has grown, this finding has been reinforced and expanded into both the retail store and virtual community contexts. Borghini et al. (2009), identified the American Girl retail store as an active brand community that inspires intense loyalty. Jones and Kim (2011) examined single-brand retail stores and found that consumers' identification with the store was related to brand community, which in turn, impacted brand loyalty. Peters and Bodkin (2021) found that retail store community engagement had a positive impact on store employee trust, store satisfaction, store commitment, and shopping enjoyment.

Although no papers on retail store community engagement have captured its impact on purchase intentions, the larger literature on virtual communities has identified the significance of this relationship. In their study of social media, Ekanayake and Abeysekera (2016) found that brand and brand community engagement predicted both brand equity and purchase intentions. Lyu and Kim (2020) also examined e-commerce activities via social media. They showed that perceived interactivity and perceived sense of community (i.e., engagement and sharing stories) related to selfbrand connection and brand commitment, which impacted brand attitudes and purchase intentions. Prentice et al.'s (2019) study showed that identification with a virtual community related to attitudinal 
and behavioural engagement with the group, which predicted purchase intentions. Dos Santos et al. (2018) examined sports sponsorship of a Soccer team and found that trust and a sense of membership within the community related to attitudes toward the team and sponsorship brands, which in turn, impacted purchase intentions. Huang et al. (2012) found that a sense of virtual community moderated the influence of comments posted on attitudes toward the product and purchase intentions. Thus, based on theory about community in marketing and its impact on attitudes and behaviours, as well as studies identifying the impact of engagement with virtual community and its relationship to attitudes and purchase intentions, the following hypotheses are posited:

Hypothesis Five: In the context of online reviews, online retail store community engagement intention has a positive impact on purchase intention.

Hypothesis Six: In the context of online reviews, online retail store community engagement intention has a positive impact on attitude toward the store.

Hypothesis Seven: In the context of online reviews, attitude toward the store has a positive impact on purchase intention.

\section{Customers Versus Store Employees}

Early on, the personal selling literature identified salesperson expertise as a factor which impacts purchasing behavior among customers (Woodside \& Davenport, 1974). The role of salesperson expertise continues to be studied, but in a more nuanced fashion. Sharma (1990), for example, examined the relationships between salesperson credibility (i.e., expertise and trust), the buyer's product evaluations, and purchase intentions. Sharma showed that salesperson credibility has a positive impact on product evaluations and purchase intentions when buyers have little prior knowledge or low expectations of the brand. Similarly, Belonax et al. (2007) found that salesperson credibility was more impactful in the context of low involvement purchases. And within a retailing context, Friedman et al. (2011) discovered that store employee expertise predicts customer satisfaction and share of wallet. When considering theory about salesperson expertise and its impact on attitudes and behaviours, as well as specific studies examining salesperson credibility and the expertise of store employees impacting satisfaction and purchase intentions, the following hypotheses are posited:

Hypothesis Eight: The impact of source credibility on online retail store community engagement intention will be stronger for store employee reviews, compared to reviews provided by other customers.

Hypothesis Nine: The impact of source credibility on purchase intention will be stronger for store employee reviews, compared to reviews provided by other customers.

There are a few studies which compare differences in consumers' perceptions when the information posted in an online review is provided by other customers versus store employees. Chen et al. (2016) examined source differences in online reviews and found that purchase intentions differed when the source of information was from other customers, a third party, or the manufacturer/retailer. Moreover, the differences varied by consumers' susceptibility to informational influence (Chen et al., 2016). For those consumers with high susceptibility to informational influence, word of mouth provided by other customers was perceived to be the most useful. In contrast, for consumers with low susceptibility to informational influence, reviews provided by all three sources were equally useful. Tata et al. (2020) also examined whether reviews provided by retailers versus a third party had a significant impact on attitudes and purchase intentions when shopping online, but they found no significant difference between these sources. Diwanji and Cortese (2020) also found no difference in perceived usefulness nor consumers' purchase intentions when videos reviews were posted by other users versus the brand. 
The variance in the perceptions of the sources in online reviews, as noted by Chen et al. (2016), may be related to trust and authenticity. Research shows that consumers are living in a postmodern, experiential economy and are actively seeking engaging experiences via their shopping and consumption behaviours (Leigh et al., 2006). Moreover, the literature on online reviews has affirmed the importance of trustworthiness of the review in impacting purchase intentions (Lee \& Hong, 2019; Reimer \& Benkenstein, 2016). Additionally, Qiao et al. (2020) found that when users are paid to post reviews, the resulting reviews are more positive yet lower quality. Thus, based on theory on authenticity and trust in online reviews, combined with Chen et al.'s (2016) study showing consumers with a high susceptibility to informational influence viewed reviews provided by other customers as more useful than reviews provided by a third party or manufacturer/retailer, the following hypotheses are posited:

Hypothesis Ten: The impact of perceived usefulness on online retail store community engagement intention will be stronger for reviews provided by other customers, compared to store employee reviews.

Hypothesis Eleven: The impact of perceived usefulness on purchase intention will be stronger for reviews provided by other customers, compared to store employee reviews.

The literature on retail store community has found that the characteristics of brand community (moral responsibility, shared consciousness, and rituals/traditions; Muñiz \& O'Guinn, 2001) exist among shoppers in the retail store context. Furthermore, this research also shows store employees are an active part of the community, in conjunction with other shoppers. Peters and Bodkin (2018) state that store employees are "brand ambassadors and members of the brand community" (p. 8) and they facilitate community by representing the brand while simultaneously building relationships with customers in the context of the retail store. More recent studies have also found that shoppers' retail store community engagement positively impacts store employee trust, which relates to their overall store satisfaction and commitment (Peters \& Bodkin, 2021). Because these findings situate the store employee as part of the retail store community in conjunction with other customers, no differences would be expected in how the relationships between engagement with the online community and its impact on attitudes toward the store and purchase intentions would vary when reviews are provided by other customers versus store employees. Thus, the following hypotheses are posited:

Hypothesis Twelve: There will be no difference in the impact of online retail store community engagement intentions on attitude toward the store, when comparing store employee reviews to reviews provided by other customers.

Hypothesis Thirteen: There will be no difference in the impact of attitude toward the store on purchase intentions, when comparing store employee reviews to reviews provided by other customers.

Hypothesis Fourteen: There will be no difference in the impact of online retail store community engagement intentions on purchase intentions, when comparing store employee reviews to reviews provided by other customers.

\section{METHODOLOGY}

\section{Data Collection}

Data were collected via an online survey built from five pre-existing scales, with established validity and reliability, along with demographic questions. The scales were modified for an online clothing context. An online clothing store was an appropriate context for studying retail store communities because these retailers often focus on community engagement as part of their missions (https://www. abercrombie.com/shop/us/about-us; https://info.lululemon.com/about/our-story). The survey was administered, via Qualtrics, to students attending a large university in the south-eastern United States. 
Respondents agreed to participate in the study in exchange for a $1 \%$ bonus point. Of the 303 initial email invitations sent, 230 responded and were randomly assigned to view one of two scenarios; 113 (49\%) were shown a scenario where other customers were the source of communication; 117 (51\%) were shown the same scenario with store employees as the source of communication. The scenarios were worded as follows:

You are shopping online at [store they provided in earlier question] for an article of clothing. You notice that the website has posted product reviews that are provided by other customers [by store employees]. These reviews discuss the quality and craftsmanship of the different styles of clothing that you are considering.

Twenty-five respondents incorrectly answered the filter questions that were embedded to ensure community engagement, resulting in a final sample of 205 (i.e., $67.6 \%$ response rate, consistent with Cook et al., 2000; 51\% were shown the 'other customers' scenario; $49 \%$ were shown the 'store employees' scenario). The majority of respondents were male (55\%), white (70\%), and employed part-time (53\%). These demographics are reflective of the larger student population at the university; thus, non-respondents had similar backgrounds. Approximately $95 \%$ of respondents indicated they spend money on clothing in a typical year; $84.4 \%$ indicated they spend "a little" to "a moderate" amount. The average response to the question, "How often do you shop for clothing at [a clothing store they named]?" was 3.1 using a scale of 1 (Not very often) to 7 (Very often).

\section{Measurement}

Online retail store community engagement intention is defined as "the consumer's intrinsic motivation to interact and cooperate with community members" in an online retail store context (Algesheimer et al., 2005, p. 21). This construct was measured using a scale developed by Lee et al. (2011), which was modified from brand community to retail store. Source credibility was defined as the extent to which consumers believe information provided by other people and organizations about products and services is based on expertise and trustworthiness (Pornpitakpan, 2004) and was measured by adapting the Flanagin and Metzger's (2000) scale of reviewer credibility. Perceived usefulness, defined as when "people tend to use or not use an application to the extent they believe it will help them" (Davis, 1989, p. 320), was measured by adapting a scale developed by Hassanein and Head (2007). Attitude toward the store is defined as the degree to which a customer holds a positive impression of an online store. Muehling et al.'s (1991) scale to assess brand attitude was adapted to ask respondents about their attitude toward the online store. Finally, purchase intention was measured by adapting a scale used by Putrevu and Lord (1994) to assess consumers' likelihood to purchase a brand in the future. Table 1 shows the full list of survey questions, along with measurement properties; each of the scales was reliable according to Cronbach's alpha.

\section{Data Analysis}

Data analysis began by assessing the validity of the constructs. First, the Kaiser-Meyer-Olkin (KMO) test was conducted to assess how well data were suited to factor analysis. The test score of .91 suggested that the sampling was adequate. Bartlett's test of sphericity yielded a p-value $<.001$. Subsequently, the researchers followed Fornell and Larcker's (1981) criteria to examine convergent and discriminant validity. First, the researchers examined the factor loadings of the constructs and found that all exceeded .70, except for one item in the online retail store community engagement construct. After validating the factor loadings, the researchers examined the average variance extracted (AVE) for each construct and found that all five constructs had an AVE greater than or equal to .60. The composite reliability value for all five constructs exceeded .70 , suggesting good internal consistency (Hair et al., 2010). The greatest percentage of variance extracted from any single factor was $23.8 \%$. To confirm the existence of different constructs in the model, the square root of the AVE of each construct was compared with the squared correlations of the construct itself and other constructs in the model (Fornell \& Larcker, 1981; Hair et al., 2010). See Table 2 for details. 
Table 1. Matrix of factor loadings, Cronbach's Alpha, average variance extracted, and composite reliability

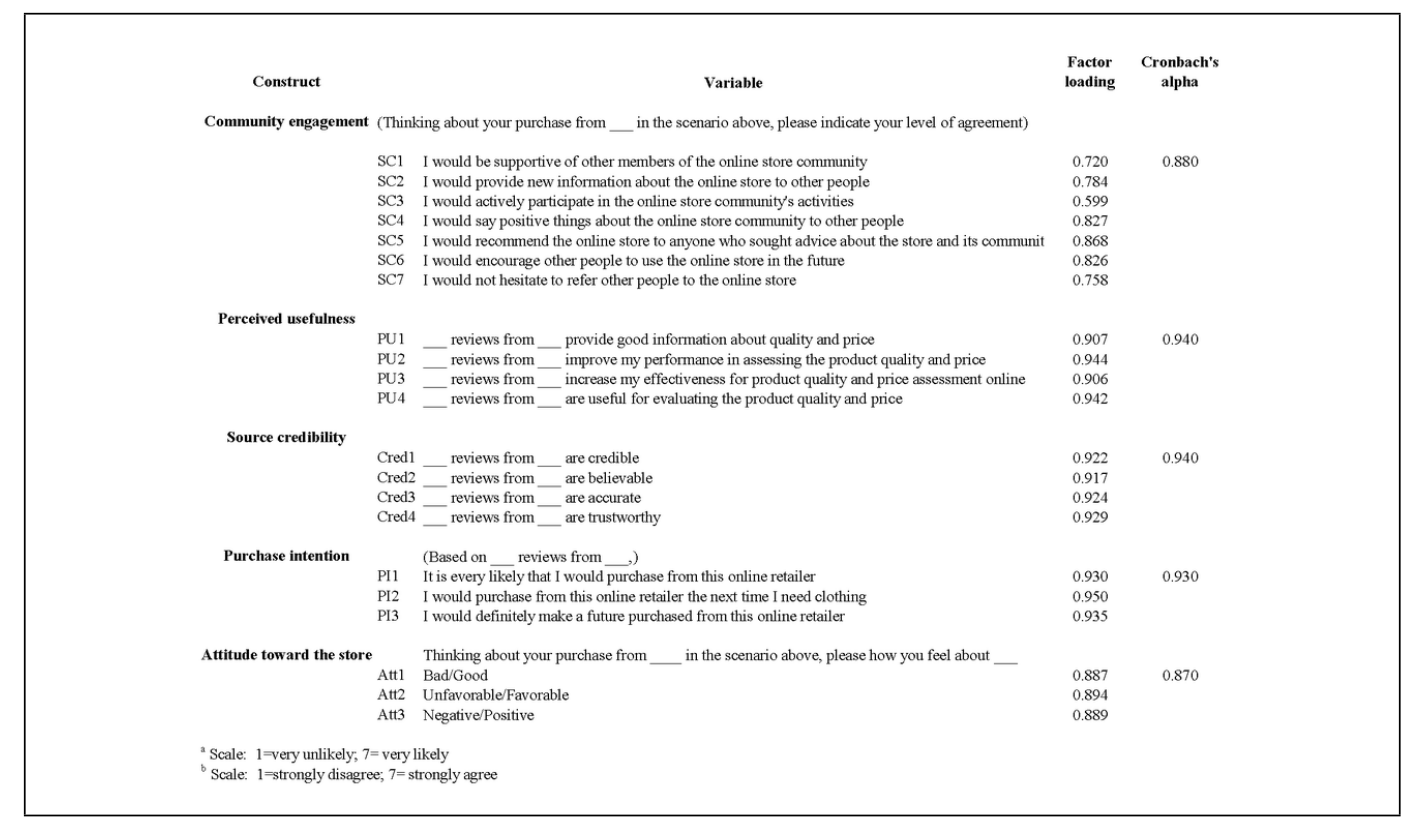

Next, the researchers created summary measures of the constructs (Martinez-Lopez et al., 2013). Hair et al. (2010) suggest that single-item measures are appropriate for simple concepts, such as behavioural outcomes, and averaging scales also can reduce model complexity (Martinez-Lopez et al., 2013). Scales used in the present study were reliable (Table 1; Cronbach's alpha ranged from .87-.94) and valid in previous research. Because the scales were reliable and drawn from previous research, Petrescu (2013) suggests the use of single-item indicators. As single items do not affect internal reliability, common method bias is minimized (Bergkvist \& Rossiter, 2007), and using common latent factor analysis, only 1.4\% common method bias was found (Gaskin, 2012).

\section{Method of Analysis}

Based on assessment of the constructs, the analysis proceeded with an examination of the proposed model, which was tested using path analysis. Path analysis allows examination of multiple regression models and is useful when assessing the fit of a priori theoretical models, because it allows examination of the significance of hypothesized relationships (Stage et al., 2004). Path analysis also provides an overall indicator of model fit (i.e., a chi-square statistic) and multiple goodness-of-fit indices. Although path analysis does not allow determination of the impact of individual scale items, the reliabilities of the variables were excellent. Finally, due to the sample size, path analysis provides greater predictive power relative to latent variable analysis. Subsequent to the examination of the proposed model, a group analysis was conducted to assess the influence of customer versus store employee reviews.

\section{RESULTS}

Path Analysis (via AMOS 26) was used to test the model and hypotheses shown in Figure 1, Model 1. Multiple indicators, averaged for each construct, were used to represent the construct (Li \& Calantone, 1998). The results of the path analysis for the original model indicated a good fit of the data. The fit statistics for the model are as follows: $\chi^{2}=5.501, \mathrm{p}=.064$, root mean residual $=.028$, goodness-offit $=.989$, adjusted goodness-of-fit $=.921$, normed fit index $=.989$, comparative fit index $=.993$, Tucker- 
Table 2. Convergent and discriminant validity (Fornell and Larcker)

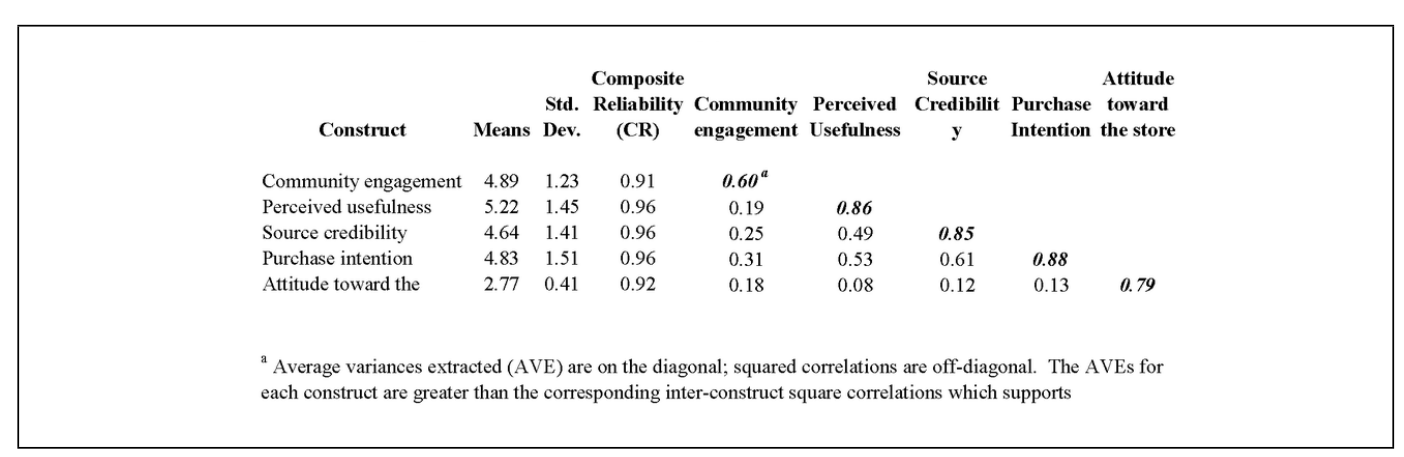

Lewis index $=.965$ incremental fit index $=.993$, and root mean square error of approximation $=.09$. The statistically non-significant $\chi^{2}(\mathrm{p}=.064)$ indicated a good fit of the model to the data, which was confirmed by the other indices. Standardized path coefficients for the model indicated that six of the seven hypotheses were significant $(\mathrm{p}<.05)$ (see Table 3 ). One of the standardized path coefficients for the hypothesis was not significant at $\mathrm{p}<.05\left(\mathrm{H}_{7}, \mathrm{p}<=.047\right)$.

The R-squared value is the proportion of variance accounted for by its predictors (Arbuckle, 2009). In the original model, approximately $26 \%$ of the variance in online retail store community engagement was explained by source credibility and perceived usefulness, and the model explained approximately $18 \%$ of the variance in attitude toward the store, and $71 \%$ of the variance in purchase intention (see Figure 1, Model 1). Based on the findings and support of the proposed hypotheses, the model appeared to provide insight into the role of online retail store community engagement intention and its ability to impact purchase intentions.

\section{Group Analysis}

The results of the path analysis for the group model (customer versus store employee reviews) indicated a good fit of the data. The fit statistics for the model are as follows: $\chi^{2}=7.146, p=.128$, root mean residual $=.03$, goodness-of-fit $=.987$, adjusted goodness-of-fit $=.899$, normed fit index $=.985$, comparative fit index $=.993$, Tucker-Lewis index $=.966$ incremental fit index $=.993$, and root mean square error of approximation $=.06$. The statistically non-significant $\chi^{2}(p=.128)$ indicated a good fit of the model to the data, which was confirmed by the other indices. Standardized path coefficients for the model indicated that six of the seven hypotheses were significant $(\mathrm{p}<.05$; see Table 3$)$. One of the standardized path coefficients for the hypothesis was not significant at $\mathrm{p}<.05\left(\mathrm{H}_{14}, \mathrm{p}<=.076\right.$ for customers and $\mathrm{p}<=.009$ for store employees).

For the customers model, approximately $22 \%$ of the variance in online retail store community engagement was explained by source credibility and perceived usefulness, and the model explained approximately $17 \%$ of the variance in attitude toward the store, and $67 \%$ of the variance in purchase intention (see Figure 1, Model 2). For the store employee model, approximately $31 \%$ of the variance in online retail store community engagement was explained by source credibility and perceived usefulness, and the model explained approximately $18 \%$ of the variance in attitude toward the store, and $73 \%$ of the variance in purchase intention (see Figure 1, Model 3). Based on the findings and support of the proposed hypotheses for the grouped analysis, the models appear to provide insight into the role of source credibility and perceived usefulness of online reviews and their ability to impact purchase intentions. Specifically, source credibility of online store employee reviews and perceived usefulness of online customer reviews significantly ( $\mathrm{p}=.007 ; \mathrm{p}=.011$, respectively) increases purchase intention. 


\section{Indirect Effects}

In addition to the models' direct effects, indirect effects of source credibility, purchase intention, and online retail store community engagement on purchase intention were examined. A mediation analysis was conducted using a bootstrap sample of 200. As seen in Table 3, mediation was identified using variance ratios (Hair et al., 2014). According to Hair et al. (2014), a complete mediating effect occurs if the proportion of the total variance that is systematic variance $(\mathrm{VAF})>.80$, a partial mediating effect if $.20<\mathrm{VAF}<.80$, and no mediating effect if $\mathrm{VAF}<.20$. For the present study, significant indirect effects $(\mathrm{p}<=.01)$ were found between source credibility and purchase intention for the original and store employee models, but no significant mediation effect was found $(\mathrm{VAF}<.20)$.

\section{CONCLUSION}

In the same way that characteristics of brand community exist within physical stores, community is in play for online retailers with respect to social shopping and reviews. This study found that consumers' perceptions of source credibility and the perceived usefulness of online reviews significantly impact an intention to engage with the online retail store community and shape consumers' attitudes toward the store and purchase intentions. The finding that source credibility relates to an intention to engage with the online retail store community is new, while the impact of credibility on purchase intentions is consistent with previous research (Assaker, 2020; Kiran \& Srivastava, 2020; Xu et al., 2020). Moreover, the study's results show that consumers' perceived usefulness significantly impacts an intention to engage with the online retail store community, which is also unique, while the impact on purchase intentions aligns with previous research (Kiran \& Srivastava, 2020; Xu et al., 2020; Ventre \& Kolbe, 2020; Zhang et al., 2021).

Online retailers may believe that including reviews as part of their websites is enough to increase sales. However, this study's results suggest that there may be a bigger picture to the influence of reviews, one in which the social nature of shopping plays an important role. Like shopping in-stores, consumers want to engage with the online retail store community via reviews. Retailers should consider ways they can increase community among consumers posting reviews and those reading them. Inviting customers to post reviews and providing suggestions for how these reviews can help other shoppers is an example of how an online retailer can encourage moral responsibility among shoppers. Asking shoppers to post reviews on a regular basis can be construed as rituals and traditions that exist within the community. And shared consciousness could be encouraged by explaining to customers that they share common interests with other shoppers and the contents of their reviews are thus helpful to the community.

This study has specific managerial implications for retailers that also extend beyond community into consumer decision making. Models such as Prospect Theory and Means End Chain Theory detail what factors motivate consumers and influence their purchase decisions. The model developed in this study similarly highlights how perceptions of online reviews (with respect to the source, credibility, and usefulness), impact socialization factors such as community engagement, which ultimately influence consumer decision making. The findings also highlight how reviews provide social proof that motivate communal engagement, which ultimately benefits the online retailer. And, in the end, retailers who utilize reviews, whether from existing customers or store employees, are viewed as more trustworthy, helpful, and social, factors which increase sales.

Another contribution of this study is that consumers evaluate reviews from other customers differently from those provided by store employees. Reviews provided by employees are viewed as more credible, most likely due to their perceived level of salesperson expertise. In contrast, reviews provided by other customers are perceived as more useful, potentially due to the authenticity and trust that comes from believing that consumers are not paid to post the reviews and thus are more objective. Some successful online retailers, like Zappos.com, rely on store employees to provide reviews; while others, like Amazon.com, rely more on customer reviews. This study highlights how 
Figure 1. Community scenario models

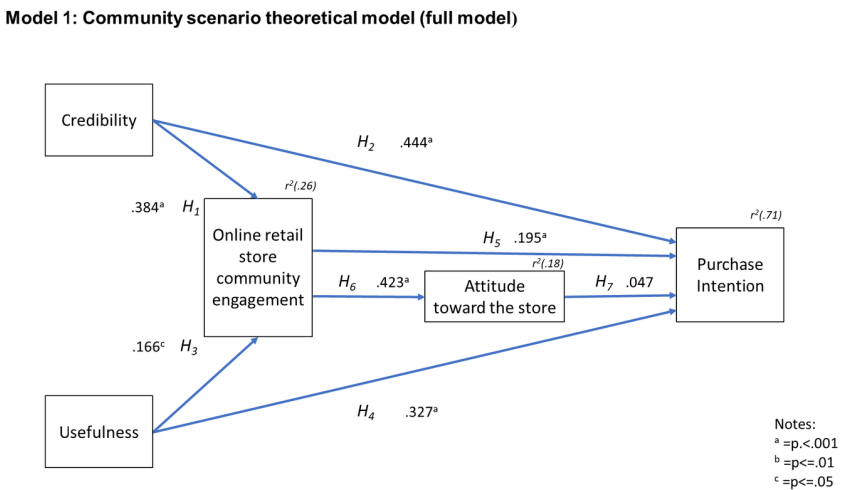

Model 2: Community scenario theoretical model (customers)

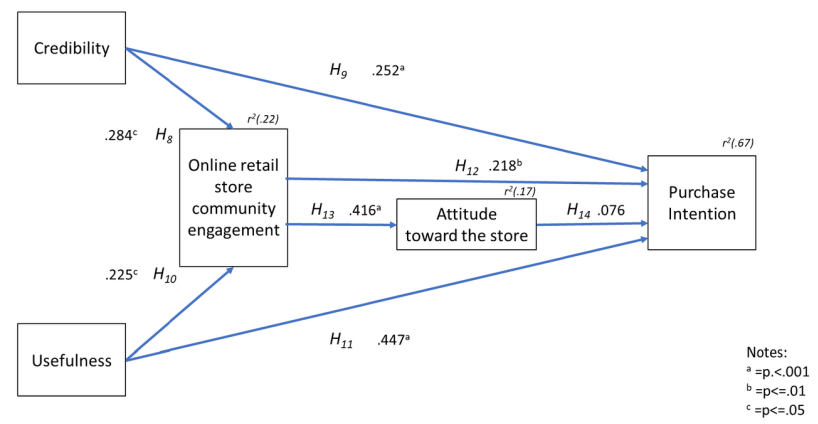

Model 3: Community scenario theoretical model (store employees)

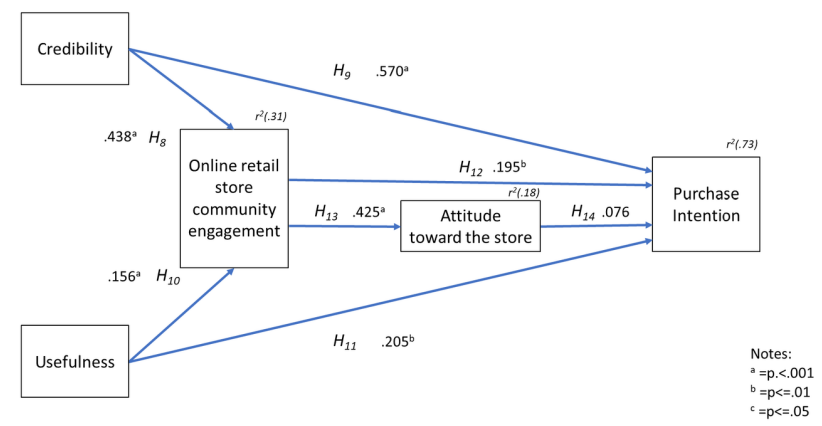

different sources for the reviews influence community engagement and purchase intentions in unique ways, which extends the literature on online reviews and source differences (Chen et al., 2016; Diwanji \& Cortese, 2020; Tata et al., 2020).

Managerially, this study's results also suggest that retailers may want to consider the strategic objectives behind utilizing reviews on their websites. Reviews provided by store employees reinforce expertise, while reviews provided by other customers appear to be more useful for shoppers. And both constructs impact online retail store community engagement and purchase intentions. Thus, depending on the objectives and resources of the online store, a retailer may only want to provide one source for reviews. For example, if the product sold is technical, such as power generators, the 


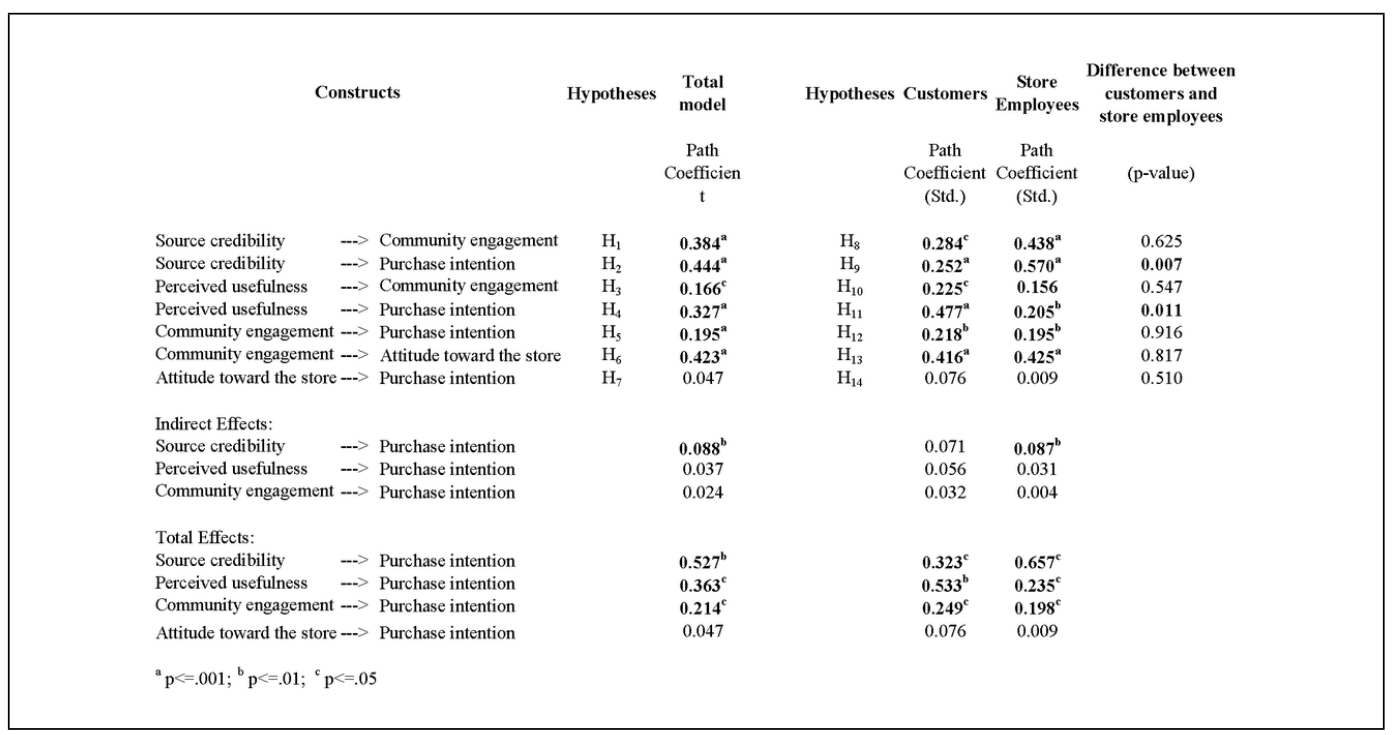

credibility of the reviewer may be especially important. Alternatively, for products such as a pair of jeans, perceived usefulness may be of greater importance. And some retailers might want to include both types of reviews to maximize the impact on community engagement and purchase intentions among shoppers on their website.

\section{Limitations and Future Research}

This study has several limitations, suggesting calls for future research. The study utilized a sample of U. S. college students, who were mostly white males and employed part-time. While college students are an appropriate sample with $91 \%$ purchasing online (Lester et al. 2006), an increasing number of older, more diverse, fully employed consumers are shopping online. Previous research also suggests that the effects of this study are likely to exist within other countries and cultures (Dos Santos et al., 2018; Ventre \& Kolbe, 2020; Zhang et al., 2016). Thus, future research should examine how various demographic groups in both the U.S. and in other countries utilize online reviews and intend to engage with community as they shop online.

While the original model was assessed using 11 indicators of significance, the root mean square error of approximation (RMSEA) was .09. While this value may be perceived as high, Chen et. al (2008, p. 476) states there "is no empirical evidence for the use of 0.05 or 0.10 as universal cut-off values to determine adequate model fit." Moreover, not all potential antecedents were included in the model, such as ease of use, social influence, cognition, and individual differences in computer use. And the structural model did not capture all possible outcomes, such as brand loyalty. Additionally, within the results, the relationship between attitude toward the store and purchase intentions was not significant. Theory of Reasoned Action (Ajzen \& Fishbein, 1999) suggests that attitudes would predict purchase intentions. However, the justification of $\mathrm{H} 7$ was based on attitudes toward the product, rather than the store. Because the respondents did not actually interact with the product, know the brand name, nor view a specific website, the absence of information about the online store may have contributed to the lack of significance for this hypothesis. 


\section{REFERENCES}

Ajzen, I., \& Fishbein, M. (1999). Attitudes and the attitude-behavior relation: Reasoned and automatic processes. European Review of Social Psychology, 11(1), 1-33. doi:10.1080/14792779943000116

Algesheimer, R., Dholakia, U. M., \& Herrmann, A. (2005). The social influence of brand community: Evidence from European car clubs. Journal of Marketing, 69(3), 19-34. doi:10.1509/jmkg.69.3.19.66363

Arbuckle, J. L. (2009). AMOS Users' Guide 18.0. SPSS.

Assaker, G. (2020). Age and gender differences in online travel reviews and user-generated-content (UGC) adoption: Extending the technology acceptance model (TAM) with credibility theory. Journal of Hospitality Marketing \& Management, 29(4), 428-449. doi:10.1080/19368623.2019.1653807

Beaulac, H. (2019, May 8). The future of social shopping. Add This Academy. Retrieved from: https://www. addthis.com/academy/the-future-of-social-shopping/

Belonax, J. J. Jr, Newell, S. J., \& Plank, R. E. (2007). The role of purchase importance on buyer perceptions of the trust and expertise components of supplier and salesperson credibility in business-to-business relationships. Journal of Personal Selling \& Sales Management, 27(3), 247-258. doi:10.2753/PSS0885-3134270304

Bergkvist, L., \& Rossiter, J. R. (2007). The predictive validity of multiple-item versus single item measures of the same constructs. JMR, Journal of Marketing Research, 44(2), 175-184. doi:10.1509/jmkr.44.2.175

Bernardino, S., Santos, J. F., Ribeiro, J. C., \& Freitas, A. (2020). Determinants of the effective use of UGC (usergenerated content) on hotel room bookings by Portuguese travellers. International Journal of Online Marketing, 10(2), 30-43. doi:10.4018/IJOM.2020040103

Borghini, S., Diamond, N., Kozinets, R. V., McGrath, M. A., Muñiz, A. M. Jr, \& Sherry, J. F. Jr. (2009). Why are themed brandstores so powerful? Retail brand ideology at American Girl Place. Journal of Retailing, 85(3), 363-375. doi:10.1016/j.jretai.2009.05.003

Carter, C. (2020). Business experts: Shopping has become a social activity amid pandemic. Retrieved from: https://www.wpri.com/business-news/business-experts-shopping-has-become-a-social-activity-amid-pandemic/

Chen, F., Curran, P. J., Bollen, K. A., Kirby, J., \& Paxton, P. (2008). An empirical evaluation of the use of fixed cut-off points in RMSEA test statistic in structural equation models. Sociological Methods \& Research, 36(4), 462-494. doi:10.1177/0049124108314720 PMID:19756246

Chen, J., Teng, L., Yu, Y., \& Yu, X. (2016). The effect of online information sources on purchase intentions between consumers with high and low susceptibility to informational influence. Journal of Business Research, 69(2), 467-475. doi:10.1016/j.jbusres.2015.05.003

Chen, M., \& Qi, X. (2015). Members' satisfaction and continuance intention: A socio-technical perspective. Industrial Management \& Data Systems, 115(6), 1132-1150. doi:10.1108/IMDS-01-2015-0023

Chih, W. H., Wang, K. Y., Hsu, L. C., \& Huang, S. C. (2013). Investigating electronic word-of-mouth effects on online discussion forums: The role of perceived positive electronic word-of-mouth review credibility. Cyberpsychology, Behavior, and Social Networking, 16(9), 658-668. doi:10.1089/cyber.2012.0364 PMID:23895466

Chou, C. H., Wang, Y. S., \& Tang, T. I. (2015). Exploring the determinants of knowledge adoption in virtual communities: A social influence perspective. International Journal of Information Management, 35(3), 364-376. doi:10.1016/j.ijinfomgt.2015.02.001

Cook, C., Heath, F., \& Thompson, R. (2000). A meta-analysis of response rates in web-or internet-based surveys. Educational and Psychological Measurement, 60(6), 821-836. doi:10.1177/00131640021970934

Corkindale, D., Ram, J., \& Chen, H. (2018). The adoption of firm-hosted online communities: An empirical investigation into the role of service quality and social interactions. Enterprise Information Systems, 12(2), 173-195. doi:10.1080/17517575.2017.1287431

Davis, F. D. (1989). Perceived usefulness, perceived ease of use, and user acceptance of information technology. Management Information Systems Quarterly, 13(3), 319-339. doi:10.2307/249008 
Diwanji, V. S., \& Cortese, J. (2020). Contrasting user generated videos versus brand generated videos versus brand generated videos in ecommerce. Journal of Retailing and Consumer Services, 54. Advance online publication. doi:10.1016/j.jretconser.2019.102024

Dos Santos, M. A., Guardia, F. R., \& Moreno, F. C. (2018). Sponsorship image transfer theory in virtual brand communities. Industrial Management \& Data Systems, 118(6), 1287-1302. doi:10.1108/IMDS-08-2017-0349

Ekanayake, S., \& Abeysekera, N. (2016). Consumer engagement with social media, brand equity and intention to purchase. Sri Lankan Journal of Management, 21(1), 83-122.

Flanagin, A. J., \& Metzger, M. J. (2000). Perceptions of Internet information credibility. Journalism \& Mass Communication Quarterly, 77(3), 515-540. doi:10.1177/107769900007700304

Fornell, C., \& Larcker, D. F. (1981). Evaluating structural equation models with unobservable variables and measurement error. JMR, Journal of Marketing Research, 18(1), 39-50. doi:10.1177/002224378101800104

Friedman, D. C., Brown, T. A., \& Taran, Z. (2011). Specialty store expertise as a driver of satisfaction and share of wallet. International Review of Retail, Distribution and Consumer Research, 21(4), 375-389. doi:10.1080/ 09593969.2011.595497

Gadgil, G., Prybutok, G., \& Prybutok, V. (2018). Qualitative investigation of the role of quality in online community support for people living with HIV and AIDS. The Quality Management Journal, 25(4), 171-185. doi:10.1080/10686967.2018.1515524

Gaskin, J. (2012, July 6). Common method bias using common latent factor. Retrieved from: https://youtu.be/ Y7Le5Vb7_jg

Hair, J. F., Black, W. C., Babin, B. J., \& Anderson, R. E. (2010). Multivariate data analysis (7th ed.). Prentice Hall.

Hair, J. F., Hult, G. T. M., Ringle, C. M., \& Sarstedt, M. (2014). A primer on partial least squares structural equation modeling. Sage.

Hajli, M. N., Sims, J., Featherman, M., \& Love, P. E. D. (2015). Credibility of information in online communities. Journal of Strategic Marketing, 23(3), 238-253. doi:10.1080/0965254X.2014.920904

Hassanein, K., \& Head, M. (2007). Manipulating perceived social presence through the web interface and its impact on attitude towards online shopping. International Journal of Human-Computer Studies, 65(8), 689-708. doi:10.1016/j.ijhcs.2006.11.018

Huang, J. H., Hsian, T. T., \& Chen, Y. F. (2012). The effects of electronic word of mouth on product judgment and choice: The moderating role of the sense of virtual community. The Journal of Applied Psychology, 42(9), 2326-2347. doi:10.1111/j.1559-1816.2012.00943.x

Jones, R., \& Kim, Y. K. (2011). Single-brand retailers: Building brand loyalty in the off-line environment. Journal of Retailing and Consumer Services, 18(4), 333-340. doi:10.1016/j.jretconser.2011.02.007

Kiran, P., \& Srivastava, A. (2020). Brunt of online product reviews over customers assessment on online platform Instagram. Adhyayan: A Journal of Management Sciences, 10(1), 14-22. 10.21567/adhyayan.v6i1.10839

Lee, D., Kim, H. S., \& Kim, J. K. (2011). The Impact of online brand community type on consumer's community engagement behaviours: Consumer-created vs. marketer-created online brand community in online social-networking web sites. Cyberpsychology, Behavior, and Social Networking, 14(1/2), 59-63. doi:10.1089/ cyber.2009.0397 PMID:21329444

Lee, J., \& Hong, I. B. (2019). Consumer's electronic word-of-mouth adoption: The trust transfer perspective. International Journal of Electronic Commerce, 23(4), 595-627. doi:10.1080/10864415.2019.1655207

Leigh, T. W., Peters, C., \& Shelton, J. (2006). The consumer quest for authenticity: The multiplicity of meanings within the MG subculture of consumption. Journal of the Academy of Marketing Science, 34(4), 481-493. doi:10.1177/0092070306288403

Lester, D. H., Forman, A. M., \& Loyd, D. (2006). Internet shopping and buying behavior of college students. Services Marketing Quarterly, 27(2), 123-138. doi:10.1300/J396v27n02_08 
Li, T., \& Calantone, R. J. (1998). The impact of market knowledge competence on new product advantage: Conceptualization and empirical examination. Journal of Marketing, 62(4), 13-29. doi:10.1177/002224299806200402

Lyu, J., \& Kim, J. (2020). Antecedents of social media-induced retail commerce activities: Impact of brandconsumer relationships and psychological sense of community. Journal of Interactive Advertising, 20(2), 119-132. doi:10.1080/15252019.2020.1769513

Martinez-Lopez, F. J., Gázquez-Abad, J. C., \& Sousa, C. M. P. (2013). Structural equation modelling in marketing and business research: Critical issues and practical recommendations. European Journal of Marketing, 47(1/2), 115-152. doi:10.1108/03090561311285484

McAlexander, J. H., Schouten, J. W., \& Koenig, H. F. (2002). Building brand community. Journal of Marketing, 66(1), 38-54. doi:10.1509/jmkg.66.1.38.18451

McIntyre, A. (2020, Feb 12). The future of online shopping is social. JDSUPRA. Retrieved from: https://www. jdsupra.com/legalnews/the-future-of-online-shopping-is-social-78164/

Muehling, D. D., Laczniak, R. N., \& Stoltman, J. J. (1991). The moderating effects of ad message involvement: A reassessment. Journal of Advertising, 20(2), 29-38. doi:10.1080/00913367.1991.10673211

Muñiz, A. M. Jr, \& O’Guinn, T. C. (2001). Brand community. The Journal of Consumer Research, 27(4), 412-432. doi:10.1086/319618

Nair, S., \& Harshavardhini, N. A. P. (2020). EWOM in international tourism: A literature review. Prerana: Journal of Management Thought \& Practice, 12(1), 29-39.

Peters, C., \& Bodkin, C. D. (2018). Community in context: Comparing brand communities and retail store communities. Journal of Retailing and Consumer Services, 45, 1-11. doi:10.1016/j.jretconser.2018.08.001

Peters, C., \& Bodkin, C. D. (2021). Retail store community and its impact on store success. International Journal of Retail \& Distribution Management, 49(6), 735-751. Advance online publication. doi:10.1108/ IJRDM-05-2020-0165

Petrescu, M. (2013). Marketing research using single-item indicators in structural equation models. Journal of Marketing Analytics, 1(2), 99-117. doi:10.1057/jma.2013.7

Pornpitakpan, C. (2004). The persuasiveness of source credibility: A critical review of five decades' evidence. Journal of Applied Social Psychology, 34(2), 243-281. doi:10.1111/j.1559-1816.2004.tb02547.x

Prentice, C., Han, X. Y., Hua, L. L., \& Hu, L. (2019). The influence of identity-driven customer engagement on purchase intention. Journal of Retailing and Consumer Services, 47, 339-347. doi:10.1016/j.jretconser.2018.12.014

Putrevu, S., \& Lord, K. R. (1994). Comparative and noncomparative advertising: Attitudinal effects under cognitive and affective involvement conditions. Journal of Advertising, 23(2), 77-90. doi:10.1080/00913367. 1994.10673443

Qiao, D., Lee, S. Y., Whinston, A. B., \& Wei, Q. (2020). Financial incentives dampen altruism in online prosocial contributions: A study of online reviews. Information Systems Research, 31(4), 1361-1375. doi:10.1287/ isre.2020.0949

Reimer, T., \& Benkenstein, M. (2016). When good WOM hurts and bad WOM gains: The effect of untrustworthy online reviews. Journal of Business Research, 69(12), 5993-6001. doi:10.1016/j.jbusres.2016.05.014

Sharma, A. (1990). The persuasive effect of salesperson credibility: Conceptual and empirical examination. Journal of Personal Selling \& Sales Management, 10(4), 71-81.

Stage, F. K., Carter, H. C., \& Nora, A. (2004). Path analysis: An introduction and analysis of a decade of research. The Journal of Educational Research, 98(1), 5-13. doi:10.3200/JOER.98.1.5-13

Tahir, M., \& Khan, W. (2020). Online review and customer purchase intention in social e-commerce context; role of trust as a mediators and source credibility as moderator. KASBIT Business Journal, 13, 61. 
Tata, S. V., Prashar, S., \& Gupta, S. (2020). An examination of the role of review valence and review source in varying consumption contexts on purchase decision. Journal of Retailing and Consumer Services, 52, 101734. Advance online publication. doi:10.1016/j.jretconser.2019.01.003

Tsai, M. T., Cheng, N. C., \& Chen, K. S. (2011). Understanding online group buying intentions: The roles of sense of virtual community and technology acceptance factors. Total Quality Management \& Business Excellence, 22(10), 1091-1104. doi:10.1080/14783363.2011.614870

Ventre, I., \& Kolbe, D. (2020). The impact of perceived usefulness of online reviews, trust, and perceived risk on online purchase intention in emerging markets: A Mexican perspective. Journal of International Consumer Marketing, 32(4), 287-299. doi:10.1080/08961530.2020.1712293

Wang, H., Chung, J. E., Park, N., McLaughlin, M. L., \& Fulk, J. (2012). Understanding online community participation: A technology acceptance perspective. Communication Research, 39(6), 781-801. doi: $10.1177 / 0093650211408593$

Widmer, B. (2020). Social shopping: What it is and why your ecommerce brand should get on board. Photoslurp. Retrieved from: https://hi.photoslurp.com/blog/social-shopping-ecommerce-brand-get-board/

Woodside, A. G., \& Davenport, J. W. Jr. (1974). The effect of salesman similarity and expertise on consumer purchasing behavior. JMR, Journal of Marketing Research, 11(2), 198-202. doi:10.1177/002224377401100212

Xie, C., Xiao, X., \& Hassan, D. (2020). Data mining and application of social e-commerce users based on big data of Internet of things. Journal of Intelligent \& Fuzzy Systems, 39(4), 5171-5181. doi:10.3233/JIFS-189002

Xu, H., Zhang, K. Z. K., \& Zhao, S. J. (2020). A dual systems model of online impulse buying. Journal of Industrial Management \& Data Systems, 120(5), 845-861. doi:10.1108/IMDS-04-2019-0214

Zhang, L., Wu, L. L., \& Mattila, A. S. (2016). Online reviews: The role of information load and peripheral factors. Journal of Travel Research, 55(3), 299-310. doi:10.1177/0047287514559032 PMID:29708106

Zhang, Z., Wang, X., \& Wu, R. (2021). Is the devil in the details? Construal-level effects on perceived usefulness of online reviews for experience services. Electronic Commerce Research and Applications, 46, 101033. Advance online publication. doi:10.1016/j.elerap.2021.101033

Cara Peters, Professor of Marketing at Winthrop University, holds a BA in Management from Luther College, and an MBA and PhD in Business Administration from the University of Nebraska. She has taught Principles of Marketing, Advertising, E-commerce, Marketing Management, Qualitative Market Research, and Personal Selling. Dr. Peters has published in numerous conference proceedings and peer-reviewed journals, including the Journal of Consumer Psychology, Consumption, Markets, and Culture, and the Journal of the Academy of Marketing Science. She has recently served as the Associate Editor for the Journal of Case Studies.

Charles Bodkin earned his PhD from Virginia Polytechnic Institute and State University. He teaches in both the undergraduate and M.B.A. programs in the Belk College. His research interests include retailing, consumer behavior and internet marketing. His research has appeared in several journals including Journal of Business Research, Industrial Marketing Management, the Journal of Marketing Management, The International Review of Retail, Distribution and Consumer Research and Corporate Communications: An International Journal. 